\title{
An Evaluation of Risk Factors for HPV (Human Papilloma Virus) and its Association with Development of Cervical Carcinoma
}

\author{
R. Rajeswari ${ }^{*}$ \\ ${ }^{1}$ Assistant Professor, Department of Microbiology, American International Institute of Medical Sciences, GBH General Hospital, \\ Udaipur-313024, Rajasthan, India
}

DOI: $10.36348 /$ sijog.2021.v04i04.002

| Received: 28.02.2021 | Accepted: 01.04.2021 | Published: 11.04.2021

*Corresponding author: Dr. R. Rajeswari

Abstract

Background: Cervical cancer is a preventable disease unlike other cancers. HPV infections have a long incubation period to cause cervical cancer. Other risk factors like early age of conception, illiteracy, low socioeconomic status, use of OCPs for a long period of time, low folate level, high parity and smoking predisposes to cervical cancer. Materials and Method: Present study aimed to identify the risk factors responsible for HPV infections and its association with development of cervical carcinoma in women of age group 20 to 65 years with history of white discharge, blood-stained discharge; heavy menstrual flow, intermenstrual spotting, and postcoital bleeding attending Gynaecology OPD samples of cervical scrapping, Pap smear, Visual Inspection with Acetic Acid (VIA) and Visual Inspection with Lugols Iodine (VILI) was taken for detection for high-risk groups for cervical cancer and its association with different risk factors. Results: HPV infection prevalence in our study was $20 \%$ among total of 100 patients. PCR positivity was highest among the age group 30-39 years. HPV infection was highest among the age group 19-20 years. Multiparous women having 3 or more children had shown high positivity for HPV - DNA. Illiterate women and women with only up to primary education had shown the highest HPV infection and it was $18 \%$. Nonvegetarian women had highest HPV infection. Major symptom of the PCR positive cases was white discharge. PCR for HPV-DNA was $100 \%$ positive in women who had cervical growth. Conclusion: Our study shows the importance of Pap smear and HPV-DNA testing of women in our country where prevalence and risk factors are extremely high. It can identify and help in preventing or treating the condition at exceedingly early stage.

Keywords: Cervical Carcinoma Risk Factors, HPV, PAP Smear, VIA, VILI.

Copyright (C) 2021 The Author(s): This is an open-access article distributed under the terms of the Creative Commons Attribution 4.0 International License (CC BY-NC 4.0) which permits unrestricted use, distribution, and reproduction in any medium for non-commercial use provided the original author and source are credited.

\section{INTRODUCTION}

Cervical cancer is the second most common malignancy among women worldwide. It is a major public health problem in India and south East Asia. According to World Health Organization cervical cancers cause more than 270,000 deaths worldwide and especially among low- and middle-income countries $85 \%$ of deaths occur [1]. In India every seven minutes a woman dies due to cervical cancer. According to ICMR about 1, 32,082 women are affected by cervical cancer and 74,118 women die due to cervical cancer.

Cervical cancer is a preventable disease unlike other cancers because cervix is easily accessible and cervical tissue is easily available for detecting premalignant lesions before it progresses to cancer.
HPV is the most common sexually transmitted infection and the infection rate over lifetime is $79 \%$. However almost all HPV infections are cleared by our immune system and only few women have persistent infection and develop precancerous cervical lesions and eventually cervical cancer $[2,3]$.

HPV infections have a long incubation period to cause cervical cancer. It takes at least 10 to 15 years to proceed from dysplasia to invasive neoplasia. Other risk factors like early age of conception, illiteracy, low socioeconomic status, use of OCPs for a long period of time, low folate level, high parity and smoking predisposes to cervical cancer. Human papilloma viruses spread easily through direct skin to mucosal contact via micro abrasions which take place during vaginal intercourse [4]. 
Cervical cancer is of two types - squamous cell carcinoma $(85 \%)$, adenocarcinoma, less commonly mixed carcinoma (Adeno-squamous). Incidence of adenocarcinoma is increasing in young women because adenocarcinoma is often missed by cytology method [5]. Hence Pap smear combined with VIA/VILI; HPVDNA detection can increase the chances of detecting preinvasive lesions. Control of cervical cancer is by primary and secondary prevention. Primary prevention involves healthy sexual practice and vaccination against HPV high risk genotypes. Secondary prevention involves screening procedures like Pap smear, VIA/VILI, and HPV-DNA detection for high-risk genotypes [6]. The aim of secondary prevention is screening for precancerous lesion and treating them.

\section{MATERIALS AND METHODS}

The purpose of this study was to identify the risk factors responsible for HPV infections and its association with development of cervical carcinoma. It was carried out in Department of Microbiology, Stanley Medical College, in association with department of Gynaecology, RSRM hospital, Stanley Medical College, Chennai between August 2012 to September 2013. During this study period women attending Gynaecology outpatient Department of age group 20 to 65 years with history of white discharge, blood-stained discharge; heavy menstrual flow, intermenstrual spotting, and postcoital bleeding were included in the study while pregnant women and with history of hysterectomy were excluded. Permission to conduct the study was obtained from the Institutional Ethical Committee of Stanley Medical College and respective hospital authorities. Informed consent was obtained from the patients before enrolling in the study.

To obtain cervical scrapping sample the cervical os and surrounding ectocervix area were cleared of excess mucus using a cotton swab and then the cervix was washed with normal saline. Using Ayers spatula cervical cells from ectocervix was obtained. The cells were immediately transferred to $2 \mathrm{ml}$ aliquot containing cold phosphate buffer saline (PBS) and then cervical cyto-brush was inserted 1.0 to $1.5 \mathrm{~cm}$ into the cervical os until the largest outer bristles of the brush touched the ectocervix. It was rotated 3 full turns in a counter clockwise direction. The brush should not be inserted completely into cervical canal. The brush was removed without touching the surrounding area and rinsed in the same aliquot containing cold PBS and then the aliquot was transferred to cold storage box containing ice packs. Strict cold temperature was maintained throughout the transportation of the sample and they were stored in deep freezer at $-70^{\circ} \mathrm{c}$ until they were processed. For the selection of subjects, preferably a woman was tested only two weeks after the first day of her last menstrual period (LMP) and not when she was menstruating, Vaginal contraceptives or douches were not used during the 48 hours before examination, Woman who abstained from intercourse 24 hours prior to examination were selected.

For Pap smear sample, the exfoliated cervical cells were collected. In this procedure a small spatula was gently rotated at the cervical os. Then the tissue obtained was smeared and spread on a glass slide and fixed using a cytofixative and then sent to the pathology laboratory for analysis of the cells.

For the Visual Inspection with Acetic Acid (VIA) with Magnification, patient was kept in lithotomy position and cervix was visualised using Cusco's speculum. After cleaning the os and ectocervix with normal saline, $3 \%$ acetic acid was applied to cervix and after one minute observed for acetowhite area under bright illumination using ring lens magnification. For Visual Inspection with Lugols Iodine (VILI) under Magnification, 5\% Lugols Iodine was applied instead of $3 \%$ acetic acid. The normal epithelium was mahogany brown in colour and if precancerous cells were present it would appear as saffron yellow in colour.

Statistical Analysis was done with PASW (Predictive Analysis Software), Statistics-18 version by statistician. $\mathrm{P}$ value obtained by Chi Square test and $\mathrm{p}<0.05$ was considered significant.

\section{RESULTS}

The prevalence of Human papillomavirus infections in our study was $20 \%$ from total of 100 patients. PCR positivity was highest among the age group 30-39 years. It was 9 cases (20 \%). HPV infection was highest among the age group 19-20 years.

Table-1: Age at Marriage with PCR Positivity

\begin{tabular}{|l|l|l|l|l|}
\hline \multirow{2}{*}{ Age in years } & \multicolumn{3}{|l|}{ Number of women } & \multicolumn{2}{l|}{ Number of women for positive for HPV DNA } \\
\cline { 2 - 5 } & No & \% & No & \% \\
\hline $17-18$ & 10 & 10 & 1 & 1 \\
\hline $19-20$ & 55 & 55 & 11 & 8 \\
\hline $21-23$ & 27 & 27 & 8 & 0 \\
\hline$>24$ & 8 & 8 & 0 & \multicolumn{2}{|l}{} \\
\hline Total & 100 & 20 & \\
\hline
\end{tabular}

Multiparous women having 3 or more children had shown high positivity for HPV- DNA by PCR. 
Table-2: Parity with PCR positivity

\begin{tabular}{|c|c|c|c|c|}
\hline \multirow[t]{2}{*}{ Parity } & \multicolumn{2}{|c|}{ Number of women } & \multicolumn{2}{|c|}{ Number of women for positive for HPV DNA } \\
\hline & No & $\%$ & No & $\%$ \\
\hline 0 & 2 & 2 & 0 & 0 \\
\hline 1 & 15 & 15 & 0 & 0 \\
\hline 2 & 59 & 59 & 8 & 8 \\
\hline$>3$ & 24 & 24 & 12 & 12 \\
\hline Total & 100 & & 20 & \\
\hline
\end{tabular}

Illiterate women and women with only up to primary education had shown the highest HPV infection and it was $18 \%$.

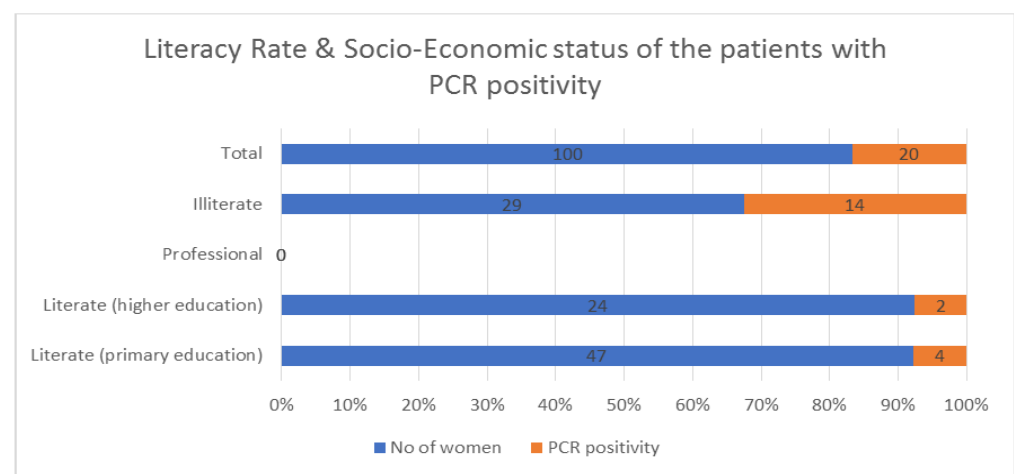

Fig-1: Literacy Rate \& Socio-Economic status of the patients with PCR positivity

Nonvegetarian women had highest HPV infection. Two women who were positive for HPV infection had Family history of cervical cancer and they were asymptomatic. Among the asymptomatic three were positive for HPV -DNA. Major symptom of the PCR positive cases was white discharge.

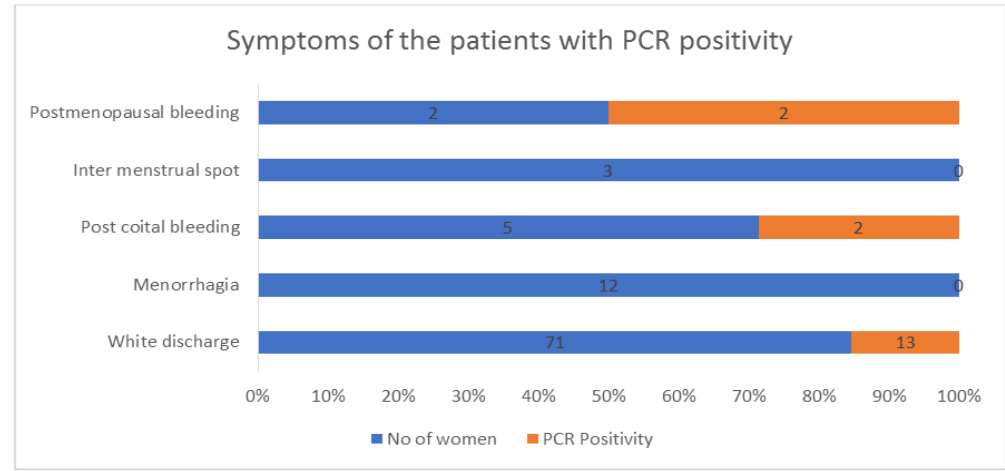

Fig-2: Symptoms of the patients with PCR positivity

PCR positivity was $11.9 \%$ among women who had healthy cervix. PCR for HPV-DNA was $100 \%$ positive in women who had cervical growth. They harboured HPV -16 and 18.

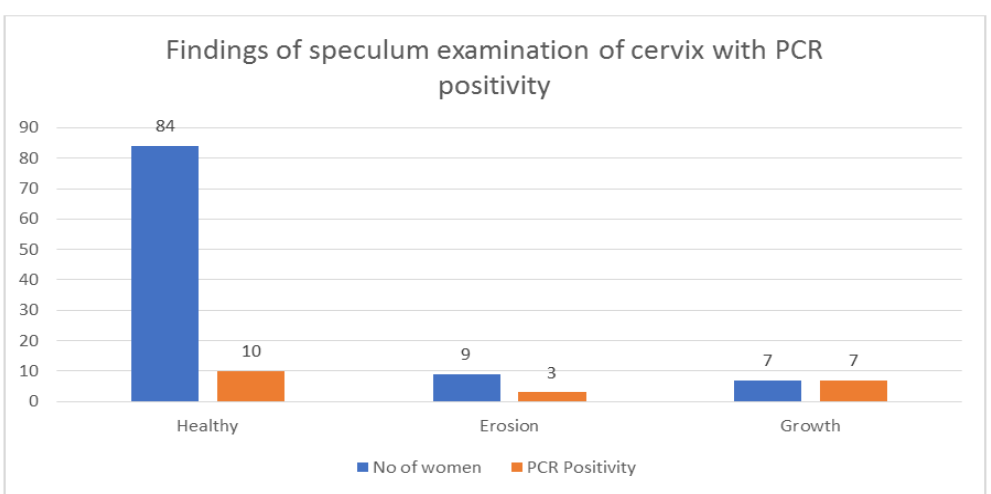

Fig-3: Findings of speculum examination of cervix with PCR positivity 
PCR for HPV-DNA was positive (13\%) among patient who had normal Pap smear. Among the women who had HSIL in Pap smear report had HPV-
DNA positivity of $7 \%$. Women who had squamous cell carcinoma were positive for HPV-DNA $16 \& 18$.

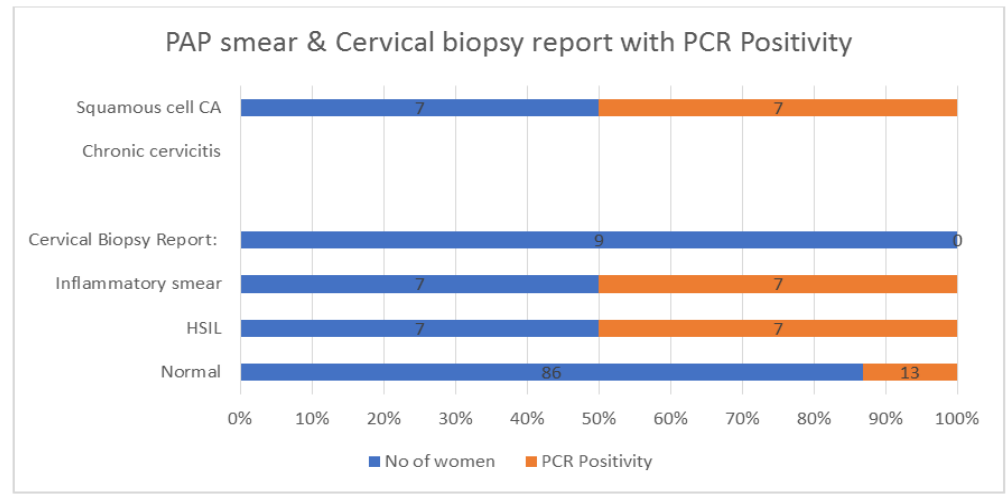

Fig-4: PAP smear \& Cervical biopsy report with PCR Positivity

\section{DISCUSSIONS}

Among the symptomatic patients the commonest age group was between 30-39 years with mean age of 38.83 years. This is well correlated with study of Aggarwal et al 2006 where the mean age is 37.5 years [7].

Early age of marriage (19-20) years in this study shows highest HPV positivity $(20 \%)$. This correlates with the study done by Anna R Giuliano et al., [8] which shows $21.1 \%$. HPV infection in our study is highest in multiparous women parity $>3$ shows $(50-$ $\%$ ). This correlates with the study done by Aggarwal et al., 2006.

In this study Women had an illiteracy rate of $70 \%$ have shown positivity for HPV infections. This correlated with Franceschi et al., [9] and Aggarwal et al., 2006. The study shows HPV positivity is associated with $90 \%$ belonging to low socioeconomic class. This is in correlation with Burd et al., 2003 [10].

In this study association with family history of CA cervix with PCR positivity is $2 \%$. But the study conducted by Shankar Narayana et al., [11] showed $9.8 \%$. Use of OCP in this study did not show association with cervical patients. Use of OCP for 5 years longer is associated with 3 -fold risk of cervical cancer. Nonvegetarian diet associated with $100 \%$ positivity for HPV infection. This is in correlation with study of Sedjo et al., 2002 [12] and Rao et al., 2010 [13].

In this study Women had an illiteracy rate of $70 \%$ have shown positivity for HPV infections. This correlated with Franceschi et al and Aggarwal et al 2006. PCR positivity was $11.9 \%$ among women who had healthy cervix for HPV-DNA was $85.7 \%$ positive in women who had cervical growth. They harboured HPV-16 and 18.HR-HPV in CA cervix is $100 \%$ in correlation with Sahar Elderdiri et al., 2013 (99.7\%) [14].

PCR for HPV-DNA was positive (13\%) among patient who had normal Pap smear. Among the women who had HSIL in Pap smear report had HPVDNA positivity of $7 \%$. Women who had squamous cell carcinoma were positive for HPV-DNA 16 \& 18 had $100 \%$. This correlates with the study done by Karolina et al., [15] where it was $98.7 \%$.

\section{CONCLUSION}

In India, every seven minutes a woman dies due to cervical cancer. Pap smear and HPV-DNA testing increases the sensitivity of diagnosing precancerous lesions of cervix before they progress to frank cancer. Pap smear and HPV -DNA testing if done together it increases the screening interval to 5 years instead of 3 every year. This study shows the importance of Pap smear and HPV-DNA testing of women in our country where prevalence and risk factors are extremely high. It can identify and help preventing or treating the condition at exceedingly early stage.

\section{ACKNOWLEDGEMENT}

We are thankful to administration of our hospital and all the supporting staff including doctors, nurses and non-medical personnel for helping us at different stages during the conduct of the study. We are grateful of all our patients for proving consent to participate in this study.

\section{Source of Funding: None}

\section{Conflict of Interest: Nil}

\section{REFERENCES}

1. Comprehensive cervical cancer prevention and control: A healthier future for girls and women Who Guidance Note -2013. 
R. Rajeswari; Sch Int J Obstet Gynec, Apr. 2021; 4(4): 90-94

2. Haverkos, H. W. (2005). Multifactorial etiology of cervical cancer: a hypothesis. Medscape general medicine, 7(4), 57.

3. Oliveira-Silva, M., Lordello, C. X., Zardo, L. M., Bonvicino, C. R., \& Moreira, M. A. (2011). Human Papillomavirus in Brazilian women with and without cervical lesions. Virology journal, 8(1), 1-6.

4. Burd, E. M. (2003). Human papillomavirus and cervical cancer. Clinical microbiology reviews, 16(1), 1-17.

5. Gomez, D. T., \& Santos, J. L. (2007). Human papillomavirus infection and cervical cancer: pathogenesis and epidemiology. Communicating current research and educational topics and trends in applied microbiology, 1, 680-8.

6. Sowjanya, A. P., Jain, M., Poli, U. R., Padma, S., Das, M., Shah, K. V., ... \& Ramakrishna, G. (2005). Prevalence and distribution of high-risk human papilloma virus (HPV) types in invasive squamous cell carcinoma of the cervix and in normal women in Andhra Pradesh, India. BMC infectious diseases, 5(1), 1-7.

7. Srivastava, S., Gupta, S., \& Roy, J. K. (2012) High prevalence of oncogenic HPV-16 in cervical smears of asymptomatic women of eastern Uttar Pradesh, India: a population-based study. Journal of biosciences, 37(1), 63-72.

8. Giuliano, A. R., Palefsky, J. M., Goldstone, S., Moreira Jr, E. D., Penny, M. E., Aranda, C., ... \& Guris, D. (2011). Efficacy of quadrivalent HPV vaccine against HPV Infection and disease in males. New England Journal of Medicine, 364(5), 401-411.
9. Franceschi, S., Rajkumar, R., Snijders, P. J. F., Arslan, A., Mahe, C., Plummer, M., ... \& Weiderpass, E. (2005). Papillomavirus infection in rural women in southern India. British journal of cancer, 92(3), 601-606.

10. Burd, E. M. (2003). Human papillomavirus and cervical cancer. Clinical microbiology reviews, 16(1), 1-17.

11. Sankaranarayanan, R., Nene, B. M., Shastri, S. S., Jayant, K., Muwonge, R., Budukh, A. M., ... \& Dinshaw, K. A. (2009). HPV screening for cervical cancer in rural India. New England Journal of Medicine, 360(14), 1385-1394.

12. Sedjo, R. L., Roe, D. J., Abrahamsen, M., Harris, R. B., Craft, N., Baldwin, S., \& Giuliano, A. R. (2002). Vitamin A, carotenoids, and risk of persistent oncogenic human papillomavirus infection. Cancer Epidemiology and Prevention Biomarkers, 11(9), 876-884.

13. Rao, K. M., Balakrishna, N., Arlappa, N., Laxmaiah, A., \& Brahmam, G. N. V. (2010). Diet and nutritional status of women in India. Journal of Human Ecology, 29(3), 165-170.

14. Gafar, S. E., Ahmed, H. G., Haroun, S. A. A., \& Mohammed, E. M. (2013). Screening for hr-hpv amongst sudanese women visiting gynecologic clinic by ish and pap. test. Management in Health, 17(2):25-30.

15. Louvanto, K., Rintala, M. A., Syrjänen, K. J., Grénman, S. E., \& Syrjänen, S. M. (2011). Incident cervical infections with high-and low-risk human papillomavirus (HPV) infections among mothers in the prospective Finnish Family HPV Study. BMC infectious diseases, 11(1), 1-11. 